[環境化学 (Joumal of Environmental Chemistry) Vol.9, No.4, pp. 969-973, 1999]

\title{
水試料中のアジピン酸エステル類の固相抽出法の検討
}

\author{
雅楽川憲子，茨木 剛，田辺 顕子，中野 友香，川田 邦明
}

新潟県保健環境科学研究所（广950-2144 新潟市兽和314-1）

[平成11年10月 6 日受理］

\section{Determination of Adipates in Water by Solid-phase Extraction Method}

\author{
Noriko UTAGAWA, Tsuyoshi IBARAKI, Akiko TANABE, Yuka NAKANO \\ and Kuniaki KAWATA
}

\author{
Niigata Prefectural Research Laboratory for Health and Environment \\ (314-1 Sowa, Niigata 950-2144)
}

[Received October 6, 1999]

\begin{abstract}
Summary
A solid phase extraction method was applied to determination of 9 adipates in water sample. A water sample of one liter added with di (2-ethylhexyl) adipate- $\mathrm{d}_{8}$ as a surrogate compound was passed through a SDB-XC disk after filtration with a glass-fiber filter.

Adipates on the disk were eluted with $10 \mathrm{~m} \ell$ of acetone and, then $10 \mathrm{~m} \ell$ of ethyl acetate. After dehydration with anhydrous sodium sulfate, the combined eluate is concentrated to $1 \mathrm{~m} \ell$ and then added with fluorene- $d_{10}$ and crysene- $d_{12}$ as the internal standards for GC/MS determination.

Adipates on suspended substances on the glass-fiber filter were extracted ultrasonically with $20 \mathrm{~m} \ell$ of acetone for $15 \mathrm{~min}$. After centrifugation at $3000 \mathrm{rpm}$ for $10 \mathrm{~min}$, the extracts were concentrated to $1 \mathrm{~m} \ell$ and then added with the internal standards for GC/MS determination.

The overall recoveries of the target compounds were $70.9 \%$ to $121 \%$ from filtrate of river water and $71.2 \%$ to $108 \%$ from suspended substances.
\end{abstract}

Key words: adipates, solid phase extraction, membrane extraction disk, water, GC/MS

\section{1. はじめに}

アジピン酸エステル類は耐寒性に優れプラスチックや ゴムの可塑剂として用いられるほか, 合成潤滑油, 化粧 品，香料等多岐にわたって使用されている ち，レザー，一般フィルム，シート等に使われている2) アジピン酸ジ（2-エチルヘキシル）（DEHA）は塩化ビ ニル樹脂用の耐寒性可塑剤として用いられており, 内分 泌機能を㭡乱する作用が疑われている

水試料中におけるアジピン酸エステル類の分析方法と しては,アジピン酸ジ (2-エチルヘキシル), アジピン
酸ジイソデシル及びアジピン酸ジブチルジグリコールに ついてへキサンで抽出する方法 ${ }^{4,5)}$ が報告されている が,アジピン酸エステル類の分析方法の報告例は少ない。 環境庁によって示された暫定マニュアル について溶媒抽出による方法が示されている。

近年用いられている固相抽出法は, 溶媒抽出法に比べ 操作が簡便であり, 溶媒使用量が少なく, 短時間で抽出 が可能である等のメリットがある。著者らは, 農薬 ${ }^{7,8)}$

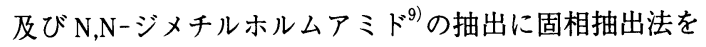
適用してきた。今回, DEHA を含む標準物質の入手可能 なアジピン酸エステル類 9 物質を対象とし, ディスク型 
固相を用いた一斉分析法を検討し，溶媒抽出と比較した ので報告する。

\section{2. 実験方法}

\section{1 試薬}

対象としたアジピン酸エステル類の一覧及びその略称 等を Table 1に示す。

アジピン酸エステル類の標準品は和光純薬製試薬特級 を用い, サロゲート物質は林純薬製アジピン酸ジ (2-工 チルヘキシル $)-\mathrm{d}_{8}\left(\mathrm{DEHA}-\mathrm{d}_{8}\right)$ を用いた。内標準物質は, $\mathrm{CDN}$ Isotopes 製フルオレン $-\mathrm{d}_{10}$ 及びクリセン $-\mathrm{d}_{12}$ を用い た。

アセトン, ヘキサン, 酢酸エチル, ジクロロメタン, メタノール, 塩化ナトリウム及び無水硫酸ナトリウムは 関東化学製残留農薬試験用を用いた。精製水は, 蒸留水 をへキサンで洗浄したものを用いた。

標準品はアセトンに溶解し, $1 \mathrm{mg} / \mathrm{m} \ell$ としたものを 標準原液とした。標準混合液は標準原液を混合し, アセ トンで各 $20 \mu \mathrm{g} / \mathrm{m} \ell$ とした。サロゲート物質はアセトン で溶解し, $100 \mu \mathrm{g} / \mathrm{m} \ell$ の溶液とした。内標準物質はアセ トンで溶解し, 各 $100 \mu \mathrm{g} / \mathrm{m} \ell$ の混合溶液とした。

\section{2 装置及び器具}

ガラス繊維ろ紙は東洋ろ紙製 GA-100（孔径 $1 \mu \mathrm{m}$, 直径 $47 \mathrm{~mm}$ ）を, ディスク型固相は, $3 \mathrm{M}$ 製 SDB-XC（直 径 $47 \mathrm{~mm}$ ）を用いた。抽出及び溶出操作は3M 製 Empore ${ }^{\mathrm{TM}}$ Disk マニホールド（6 連式）を用いた。ガス クロマトグラフ／質量分析装置は島津製作所製 GCMS-QP5050A を用いた。

\section{3 分析方法}

試料水 $1 \ell$ をガラス繊維ろ紙でろ過して得られたろ液 にサロゲート物質 $\left(\mathrm{DEHA}-\mathrm{d}_{8}\right) 1 \mu \mathrm{g}$ を添加し, 予めア セトン, メタノール及び精製水各 $10 \mathrm{~m} \ell$ でコンディショ ニングしたディスクに通水する。ディスクを精製水 $10 \mathrm{~m} \ell$

Table 1 Monitoring ions of target adipates

\begin{tabular}{llcc}
\hline \multirow{2}{*}{ Compound } & Abbrs. & \multicolumn{2}{c}{ Monitoring ion $(\mathrm{m} / \mathrm{z})$} \\
\cline { 3 - 4 } & & $\mathrm{Q}$ & $\mathrm{C}$ \\
\hline Dimetyl adipate & DMA & 114.1 & 143.2 \\
Divinyl adipate & DVA & 111.1 & 155.1 \\
Diethyl adipate & DEA & 111.1 & 157.1 \\
Diisopropyl adipate & DIPA & 129.1 & 171.1 \\
Dipropyl adipate & DPA & 129.1 & 171.1 \\
Diisobutyl adipate & DIBA & 129.1 & 185.1 \\
Dibutyl adipate & DBA & 129.1 & 185.1 \\
Di(2-ethylhexyl)adipate & DEHA & 129.1 & 147.2 \\
Diisononyl adipate & DINA & 129.1 & 255.2 \\
Di(2-ethylhexyl)adpate-d & DEHA-d 8 & 137.2 & \\
\hline
\end{tabular}

Q:quantification ion, C:confirmation ion
で洗浄後，15分間通気することにより水分を除去する。 アセトン及び酢酸エチル各 $10 \mathrm{~m} \ell て ゙$ 溶出し, 得られた溶 出液を合わせ, 少量の無水硫酸ナトリウムで脱水した後, 清浄な窒素ガスを穏やかに吹き付け $1 \mathrm{~m} \ell$ に濃縮し, 内 標準物質（フルオレン $-\mathrm{d}_{10}$ 及びクリセン $-\mathrm{d}_{12}$ ) を添加し, GC/MS で定量する。

ろ紙上の浮遊物については, 無水硫酸ナトリウム $4 \mathrm{~g}$ を底に入れた遠心管を用いて $3000 \mathrm{rpm}$ で 5 分間遠心する ことにより脱水後 ${ }^{10)}$, サロゲート物質 $1 \mu \mathrm{g}$ を添加し, アセトン $20 \mathrm{~m} \ell$ を加え15分間超音波抽出を行い, $3000 \mathrm{rpm}$ で10分間遠心分離することにより抽出液を分取 する。この抽出操作を 2 回繰り返し, 得られた抽出液を 合わせ, $30^{\circ} \mathrm{C}$ 以下の湯浴中ロータリーエバポレーターを 用いて濃縮し, さらに清浄な窒素ガスを穏やかに吹き付 け $1 \mathrm{~m} \ell に$ 濃縮し, 内標準物質を添加した後, GC/MSで 定量する。

溶媒抽出による方法 ${ }^{6)}$ は, 試料水 $1 \ell$ にサロゲート物 質 $1 \mu \mathrm{g}$ を添加し, 塩化ナトリウム $50 \mathrm{~g}$ を加え溶解した 後, ヘキサン $100 \mathrm{~m} \ell$ を加え 5 分間振とう抽出し, へキサ ン層を分取する。再び水層にへキサン $100 \mathrm{~m} \ell$ を加え, 同 様な操作を繰り返す。得られたへキサン層は無水硫酸ナ トリウムで脱水後, $30^{\circ} \mathrm{C}$ 以下の湯浴中ロータリーエバポ レーターを用いて $10 \mathrm{~m} \ell$ まで濃縮する。さらに清浄な窒 素ガスを穏やかに吹き付け $1 \mathrm{~m} \ell$ とし, 内標準物質を添 加した後, GC/MS で定量する。

\section{4 GC/MS 測定}

GC/MS 測定条件を Table 2に, 対象物質のクロマトグ ラムの例を Fig. 1に示す。

\section{3. 結果及び考察}

\section{1 溶出溶媒の検討}

ディスクからの溶出溶媒として,アセトン, ヘキサン, 酷酸エチル及びジクロロメタンの 4 種類について検討し た。精製水 $1 \ell$ にアジピン酸エステル各 $0.1 \mu \mathrm{g}$ を添加し,

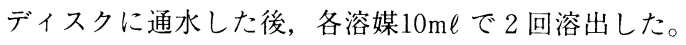
得られた回収率を Table 3に示す。サロゲート物質の回 収率も併せて示す。検討した溶媒のうち，アセトンでは 81 112\% と高い回収率が得られ, 次いで酢酸エチルで あった。アセトンは 1 回目の $10 \mathrm{~m} \ell$ の溶出で, DMA 以外 の対象物質は72〜108\%と良好に回収できた。そのうち， 特にDEA，DIPA，DPA，DIBA 及びDBAの 5 物質は良 好に回収できた。酢酸エチルを用いたときの溶出は 1 回 目で, DMA 以外の対象物質の回収率は78 93\% と良好 に回収でき，2 回目ではほとんど溶出されなかった。対 象物質のうち, DBA, DEHA 及び DINA は良好に回収で き,アセトンで抽出したものに比べ, 高分子量の 3 物質 についてより良好に回収することが可能であった。ジク 


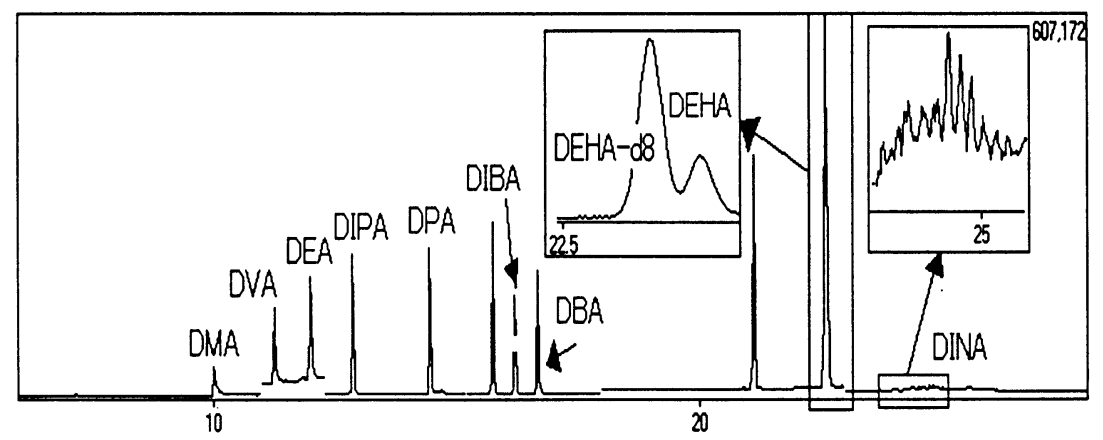

Fig. 1 Typical chromatogram of adipates

ロロメタンについては酢酸エチルを用いた場合の回収率 より低いが，同様な傾向がみられた。これに対して，へ キサンを用いたときの 1 回目の溶出では, DMA を除く 対象物質の回収率は68～85\%に留まり，溶出には 2 回の 計 $20 \mathrm{~m} \ell$ を用いる必要があることがわかった。

以上のことから，ディスクからの溶出溶媒として，ア セトン及び酢酸エチル各 $10 \mathrm{~m} \ell$ を用いることとした。

\section{2 添加回収試験}

信濃川で採水した河川水 $1 \ell$ をガラス繊維ろ紙でろ過 し, アジピン酸エステル各 $0.3 \mu \mathrm{g}$ を添加し, 分析を行っ た。添加回収試験の結果を Table 4に示す。対象物質は 全て $70 \%$ 以上と比較的良好な回収率が得られた。精製水 に添加した場合の結果（Table 3）に比べ, DHEA 及び DINA を除く物質の回収率は増加した。この原因として,

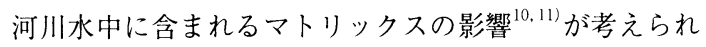
た。

溶媒抽出による方法における添加回収試験の結果を Table 4に併せて示す。溶媒抽出では回収率の悪かった DMA (32\%) については, ディスク抽出法によると $82.8 \%$
Table 2 Conditions for GC/MS

\begin{tabular}{ll}
\hline GC/MS & GCMS-QP5050A(Simadzu) \\
Column & HP-5 Trace Analysis \\
& $30 \mathrm{~m} \times 0.25 \mathrm{~mm}$ tickness $0.25 \mu \mathrm{m}$ \\
Injection temperature & $280^{\circ} \mathrm{C}$ \\
Column temperature & $60^{\circ} \mathrm{C}(1 \mathrm{~min}) \rightarrow 10^{\circ} \mathrm{C} / \mathrm{min} \rightarrow 300^{\circ} \mathrm{C}(5 \mathrm{~min})$ \\
Injection mode & $\mathrm{Splitles8}($ purge on time $1 \mathrm{~min})$ \\
Carrier gas & $\mathrm{He}$ \\
Column pressure & $6 \mathrm{kPa}(0 \mathrm{~min}) \rightarrow 200 \mathrm{kPa} / \mathrm{min} \rightarrow 70 \mathrm{kPa}(0.5 \mathrm{~min})$ \\
& $\rightarrow 200 \mathrm{kPa} / \mathrm{min} \rightarrow 6 \mathrm{kPa}(0 \mathrm{~min}) \rightarrow 2 \mathrm{kPa} / \mathrm{min}$ \\
& $\rightarrow 54 \mathrm{kPa}(4.86 \mathrm{~min})$ \\
Interface temperature & $280^{\circ} \mathrm{C}$ \\
Ionization energy & $70 \mathrm{eV}$
\end{tabular}

と良好に回収できた。ディスク抽出法と溶媒抽出法にお ける検出下限值 ${ }^{13)}$ を Table 4に示す。いずれの方法でも DEHA は0.09〜0.1 $\mu \mathrm{g} / \ell$ とやや高い值であったが, DEHA を除く物質の検出下限值は $0.01 \sim 0.03 \mu \mathrm{g} / \ell$ であっ た。

一方，浮遊物を捕集したろ紙に，アジピン酸エステル 各0.1 $\mu \mathrm{g}$ を添加し, 浮遊物からの添加回収試験を行った。 その浮遊物についての添加回収試験の結果及び検出下限 值を Table 5に示す。浮遊物についても，対象物質の全

Table 3 Recoveries of adipates from membrane extraction disk

\begin{tabular}{|c|c|c|c|c|c|c|c|c|c|}
\hline \multirow{4}{*}{ Compound } & \multirow{4}{*}{$\begin{array}{l}\text { Added } \\
(\mu \mathrm{g})\end{array}$} & \multicolumn{8}{|c|}{ Recovery (\%) } \\
\hline & & \multicolumn{8}{|c|}{ Extract solvent } \\
\hline & & \multicolumn{2}{|c|}{ Acetone } & \multicolumn{2}{|c|}{ Hexane } & \multicolumn{2}{|c|}{ Ethyl acetate } & \multicolumn{2}{|c|}{ Dichlonomethane } \\
\hline & & $10 \mathrm{ml}$ & $20 \mathrm{ml}$ & $10 \mathrm{ml}$ & $20 \mathrm{ml}$ & $10 \mathrm{ml}$ & $20 \mathrm{ml}$ & $10 \mathrm{ml}$ & $20 \mathrm{ml}$ \\
\hline $\mathrm{DMA}$ & 0.1 & 46.5 & 91.8 & 22.2 & 38.3 & 26.3 & 48.7 & 32.5 & 68.4 \\
\hline DVA & 0.1 & 77.9 & 84.5 & 74.1 & 826 & 78.7 & 85.6 & 67.1 & 73.4 \\
\hline DEA & 0.1 & 94.3 & 99.3 & 79.6 & 88.7 & 83.0 & 88.1 & 75.3 & 79.6 \\
\hline DIPA & 0.1 & 85.6 & 90.4 & 77.6 & 86.3 & 821 & 85.3 & 78.6 & 81.4 \\
\hline DPA & 0.1 & 96.1 & 101 & 81.9 & 90.2 & 85.9 & 88.5 & 86.3 & 88.4 \\
\hline DIBA & 0.1 & 89.4 & 93.8 & 76.7 & 83.3 & 83.7 & 84.0 & 89.3 & 89.4 \\
\hline DBA & 0.1 & 108 & 112 & 81.6 & 87.2 & 928 & 91.4 & 104 & 103 \\
\hline DEHA & 0.1 & 78.7 & 83.1 & 85.6 & 95.1 & 85.2 & 83.9 & 68.9 & 68.2 \\
\hline DINA & 0.1 & 74.3 & 85.4 & 68.6 & 83.6 & 83.9 & 88.0 & 78.6 & 83.9 \\
\hline DEHA- $d_{8}$ & 1.0 & 722 & 81.4 & 77.8 & 92.2 & 79.5 & 83.9 & 61.3 & 65.9 \\
\hline
\end{tabular}


Table 4 Recoveries of adipates added to river water

\begin{tabular}{|c|c|c|c|c|c|c|c|c|}
\hline \multirow[b]{2}{*}{ Compound } & \multicolumn{4}{|c|}{ Membrane extraction disk } & \multicolumn{4}{|c|}{ Solvent extraction } \\
\hline & $\begin{array}{l}\text { Added } \\
(\mu \mathrm{g})\end{array}$ & $\begin{array}{l}\text { Recovery } \\
(\%)\end{array}$ & $\begin{array}{l}\text { RSD } \\
(\%)\end{array}$ & $\begin{array}{l}\text { DL } \\
(\mu \mathrm{g} / \mathrm{L})\end{array}$ & $\begin{array}{l}\text { Added } \\
(\mu \mathrm{g})\end{array}$ & $\begin{array}{l}\text { Recovery } \\
\text { (\%) }\end{array}$ & $\begin{array}{l}\text { RSD } \\
(\%)\end{array}$ & $\begin{array}{l}\mathrm{DL} \\
(\mu \mathrm{g} / \mathrm{L})\end{array}$ \\
\hline DMA & 0.1 & 82.8 & 7.7 & 0.02 & 0.3 & 32.0 & 10.3 & 0.01 \\
\hline DVA & 0.1 & 88.0 & 5.8 & 0.01 & 0.3 & 80.8 & 10.8 & 0.02 \\
\hline DEA & 0.1 & 89.0 & 3.3 & 0.01 & 0.3 & 76.6 & 15.3 & 0.01 \\
\hline DIPA & 0.1 & 87.8 & 1.9 & 0.01 & 0.3 & 89.1 & 13.1 & 0.01 \\
\hline DPA & 0.1 & 101 & 3.4 & 0.01 & 0.3 & 90.3 & 15.1 & 0.01 \\
\hline DIBA & 0.1 & 121 & 7.2 & 0.02 & 0.3 & 101 & 15.8 & 0.01 \\
\hline DBA & 0.1 & 99.1 & 11.6 & 0.03 & 0.3 & 100 & 16.2 & 0.01 \\
\hline DEHA & 0.1 & 70.9 & 17.1 & 0.1 & 0.3 & 93.0 & 16.0 & 0.09 \\
\hline DINA & 0.1 & 71.5 & 15.8 & 0.03 & 0.3 & 84.2 & 8.2 & 0.03 \\
\hline DEHA-d $\mathbf{d}_{\mathbf{g}}$ & 1.0 & 72.0 & 15.2 & & 1.0 & 94.4 & 12.8 & \\
\hline
\end{tabular}

Table 5 Recoveries of adipates added to suspended substances on glass-fiber filter

\begin{tabular}{lllll}
\hline Compound & $\begin{array}{l}\text { Added } \\
(\mu \mathrm{g})\end{array}$ & $\begin{array}{l}\text { Recovery } \\
(\%)\end{array}$ & $\begin{array}{l}\text { RSD } \\
(\%)\end{array}$ & $\begin{array}{l}\mathrm{DL} \\
(\mu \mathrm{g} / \mathrm{L})\end{array}$ \\
\hline DMA & 0.1 & 71.7 & 11.7 & 0.03 \\
DVA & 0.1 & 71.7 & 7.9 & 0.02 \\
DEA & 0.1 & 85.2 & 3.0 & 0.01 \\
DIPA & 0.1 & 71.2 & 3.9 & 0.01 \\
DPA & 0.1 & 90.1 & 7.5 & 0.02 \\
DIBA & 0.1 & 108 & 6.0 & 0.02 \\
DBA & 0.1 & 83.8 & 7.3 & 0.02 \\
DEHA & 0.1 & 81.9 & 13.5 & 0.03 \\
DINA & 0.1 & 95.5 & 6.6 & 0.1 \\
DEHA-d & 1.0 & 92.5 & 3.4 & \\
\hline n=6 & & & &
\end{tabular}

DL : detection limit

てが70\%以上と比較的良好な回収率が得られた。検出下 限值 ${ }^{13)}$ は0.01（DEA 及び DIPA） 0.1 (DINA) $\mu \mathrm{g} / \ell$ の範 囲であった。

以上のことから，アジピン酸エステル類については ディスクを用いた方法でも有効な手段であると評価でき た。

本分析法を信濃川で採水した河川水に適用した。その 結果, いずれの物質も検出されなかった。

(本報告のうち DBA の溶媒抽出法については，平成10 年度環境庁環境保健部環境安全課の委託によって行った ものである。関係各位に深謝します。)

\section{要 約}

プラスチックの可塑剤等として用いられるアジピン酸 エステル 9 種類について, ディスク型固相を用いた一斉 分析を検討した。溶媒抽出についても併せて検討した。 ディスクからの溶出溶媒について検討した結果, アセ卜 ン及び酢酸エチル各 $10 \mathrm{~m} \ell$ を用いることとした。河川水 を用いて，ディスク型固相及び溶媒抽出により添加回収
試験を行った結果，低分子量の DMA を除くアジピン酸 エステル類についてはおおむね同様の結果が得られたこ とから、ディスクを用いた方法でも溶媒抽出による方法 と同等であると評価できた。

\section{文 献}

1）新化学インデックス1997年度版，化学工業日報社, pp.7-8 (1997)

2） 10889 の化学商品, 化学工業日報社, pp.830-831 (1989)

3）環境庁リスク対策検討会：「環境ホルモン 外因性 内分泌攪乱化学物質問題に関する研究班中間報告 書」, pp.85-86，環境新聞社，東京 (1997)

4）荻野泰夫, 斉藤直已, 長尾万治：化学物質環境調査 (分析法) に関する研究, 岡山県環境保健センター 年報，3，167-172（1979）

5）環境庁環境保健部環境安全課：平成 6 年度化学物質 分析法開発調查報告書, pp.127-154（1995）

6）環境庁水質保全局水質管理課：外因性内分泌攪乱化 学物質調查暫定マニュアル, pp.V-1-8 (1998)

7) Tanabe, A., Mitobe, H., Kawata, K. and Sakai, M.: Monitoring of herbicides in river water by gas chromatography-mass spectrometry and solid-phase exraction. J. Chromatogr. A, 754, 159-168 (1996)

8）田辺顕子，茨木 剛，家合浩明，川田邦明，坂井正 昭：ディスク型固相抽出法による環境水中の農薬類 の分析，環境化学， 9，607-615（1999）

9）茨木 剛, 水戸部英子, 川田邦明, 坂井正昭：固相

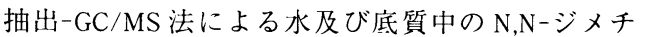
ルホルムアミドの定量, 環境化学, 9, 407-410 (1999)

10）田辺顕子，水戸部英子，川田邦明，坂井正昭：環境 水中の粒子状物質に含まれる農薬一斉定量, 分析化 学, 8, 481-489 (1998) 
11) Holland, P.T., McNaughton, D.E. and Malcolm, C.P.: Multiresidue Analysis of Pesticides in Wines by Solid-Phase Extraction, J. Assoc. Off. Anal. Chem., 77, 79-86 (1994)

12）奥村為男：キャピラリー・GC/MSによる水中の農
薬及びその酸化生成物の定量一標準液の PEG 共注 入法一, 環境化学, 5, 575-583（1995）

13) Massart, D.L., Vandeginste, B.G.M., Deming, S.N., Michotte, Y. and Kaufman, L.: Chemometrics: a testbook, pp112-113, Elsevier, Amsterdam (1988) 